\title{
Design and test water intake monitor to improve human's well-being
}

\author{
Xinyang $\operatorname{Li}^{1}$ \\ 1 The High School Affiliated to Beijing Normal University, Beijing 100052, China \\ *Correspondence: 44328817@qq.com
}

(Received: 10/11/2019; Accepted: 03/17/2020; Published: 04/15/2020)

DOI: https://doi.org/10.37906/isteamc.2020.4

\begin{abstract}
Water is a substance that the human body needs in order to survive. Drinking the right amount of water has many health benefits, including maximum physical performance, high energy levels, and improved brain function. Dehydration occurs when the body uses or loses more fluid than it takes in. When dehydration happens, the body doesn't have enough fluids in it to carry out its normal functions. In older adults, dehydration is the most common disorder that can occur. As adults get older, the body's fluid reserve becomes smaller, and the ability to process and conserve water is reduced. We have designed a sensor to track to the amount of water put into the body. This monitor will help seniors, especially those in a nursing home, to track their daily water intake. The sensor works with other personalized data to create a dashboard to their medical provider for better health care. There are still some limitations of the sensor. We will continue to improve the accuracy of measurement and the material we used.
\end{abstract}

Keywords: water intake monitor; hydration; older adults

\section{Introduction}

Water is essential for life. The human body is composed of 25 percent solid matter and 75 percent water. Brain tissue is said to consist of 85 water (Batmanghelidj, 1997). Water represents a critical nutrient, the absence of which will be lethal within days. The amount of water a person should drink varies with different people. On average, people should drink about $1200 \mathrm{ml}$ of water a day (Chinese Nutrition Society, 2017). However, most people who are healthy can drink water whenever they feel thirsty. Studies show that there are a long list of benefits of drinking enough water, such as helping to maximize physical performance, improving energy levels and brain function, and preventing a ranger of chronic illness.

Dehydration occurs when the body uses or loses more fluid than it takes in, and the body doesn't have enough water and other fluids to carry out its normal functions. Dehydration is the most common fluid or electrolyte disorder among older adults. Humans seem to lose their thirst sensation and the critical perception of needing water. Not recognizing their water need, they become gradually, increasingly, and chronically dehydrated with the progress of aging (Batmanghelidj, 1997). As adults age, the body's fluid reserve becomes smaller, the ability to conserve water is reduced, and the thirst sensation becomes less acute. These problems are compounded by chronic illnesses such as diabetes, dementia, and by the use of certain medications.

Water can help improve a human's well-being. However, people can easily forget to drink water. It is better to understand how much water the human body needs and track daily water intake. There are several stages to water regulation of the body in the different phases of life (Batmanghelidj, 1997). We focus 
on hydration effects on older adults. Because the elderly have low water reserves, it may be prudent for them to drink water regularly, even when they may not feel thirsty, and to moderately increase their salt intake when they sweat. Better education on these principles may help prevent sudden hypotension, stroke, or abnormal fatigue, which can lead to a vicious circle and eventually hospitalization (Popkin, D'Anci, \& Rosenberg, 2010). We have designed a water intake monitor to help older adults, especially those who are living in a nursing home, to track their daily water intake. It works with other data to provide a dashboard to their medical provider for better health care.

\section{Research Design, Data collection, and Analysis Methods}

The water intake monitor consist of an angle sensor that measures the tilt angle of the cup. To properly model the amount of drinking water, we need to first relate the voltage output from the angle sensor to the tilt angle of the cup, then the angle can then be related to the amount of drinking water to monitor the older adults' water intake. As a result, this paper details the following 4 studies.

\subsection{Design of Study 1: Relationship between Angle and Voltage}

A gradienter was used to measure the angle data, which was mounted to the bottom of the cup. First, the level calibration was adjusted to zero by slowing moving an empty cup such that the gradienter reached the corresponding value and remained stable. The Pro Micro angle sensor was connected to the Arduino to proofread the serial port and import the program. The serial monitor was used to measure the voltage values. Multiple angles were selected for the experiment, and the mode was screened from the derived values. The function relationship between the angle and the voltage value was analyzed and plotted.

\subsection{Design of Study 2: Relationship between Angle and Amount of Drinking Water}

The tested older adult lifted the cup slowly and took a sip of water while the water level was parallel to the table. The voltage values can be measured and observed through the serial monitor. Afterwards, the water cup was placed on the electronic scale to weigh the mass. Then the value was compared to the total volume to get the volume of the water drunk. Multiple values were recorded, until the whole cup of water was finished. The voltage value at each point was screened to obtain the corresponding mode. According to the relationship between the angle and the voltage value, the actual function relationship between the drinking angle and amount was analyzed and plotted.

\subsection{Design of Study 3: Full Day Water Drinking Simulation}

After the connection was built, the water could be drunk normally. The voltage values can be measured through the serial monitor. After one day observation, the water drinking time was measured and plotted on scatter plots at different points in time. The total daily water drinking amount of the older adult was calculated according to the relationship between the angle and the amount of water drinking.

\subsection{Design of Study 4: Initial Test of the Full System with elder adults}

Five older adults were selected as test subjects. The cups with sensors were used to drink water, and the voltage values were imported through the serial port monitor. The health status of the elder adults was analyzed by recording data.

\section{Experimental Results and Analysis}

\subsection{Basic Hypothesis}

The physical conditions of the older adults are stable when they just finish the physical examination. The water drinking movement is relatively uniform with small changes. They have fixed water drinking habits and other behavior patterns every day. After the experimental instrument has been verified, the 
volume and error of the irregular part of the measuring glass can be neglected. In addition, the error caused by the experimental position are also negligible. Assuming that the mode is valid, the error can be negligible if it is within $1 / 100$. The data measured at each sampling point is basically accurate and reliable.

\subsection{Data Collection}

3.2.1 Relationship between Angle and Voltage Value

Table 1. Relationship between Angle and Voltage Value

\begin{tabular}{llllllllllllllll}
\hline Angle & 0 & 15 & 20 & 25 & 30 & 35 & 40 & 45 & 50 & 55 & 60 & 65 & 70 & 75 & 90 \\
\hline Value & 266 & 269 & 270 & 271 & 274 & 276 & 282 & 287 & 291 & 296 & 300 & 305 & 308 & 313 & 332 \\
\hline
\end{tabular}

3.2.2 Relationship between Angle and Water Drinking Amount

Table 2. Relationship between Angle and Water Drinking Amount

\begin{tabular}{|c|c|c|c|c|c|}
\hline $\begin{array}{l}\text { Volume } \\
\text { Variation } \\
(\mathrm{ml})\end{array}$ & $\begin{array}{l}\text { Mass } \\
(\mathrm{g})\end{array}$ & $\begin{array}{l}\text { Angle } \\
\left({ }^{\circ}\right)\end{array}$ & $\begin{array}{c}\text { Voltage Value } \\
\text { (Baud) }\end{array}$ & $\begin{array}{l}\text { Angle } \\
(\pi)\end{array}$ & $\begin{array}{c}\text { Total Water } \\
\text { Drinking } \\
\text { amount } \\
\text { (ml) }\end{array}$ \\
\hline Initial & 706 & 0.00 & 266 & & \\
\hline 43 & 663 & 7.00 & 268 & 0.12 & 43 \\
\hline 62 & 601 & 21.00 & 272 & 0.37 & 105 \\
\hline 37 & 564 & 35.00 & 276 & 0.61 & 142 \\
\hline 55 & 509 & 40.28 & 281 & 0.70 & 197 \\
\hline 38 & 471 & 45.19 & 286 & 0.79 & 235 \\
\hline 53 & 418 & 50.10 & 291 & 0.87 & 288 \\
\hline 41 & 377 & 52.07 & 293 & 0.91 & 329 \\
\hline 53 & 324 & 56.98 & 298 & 0.99 & 382 \\
\hline 53 & 271 & 64.84 & 306 & 1.13 & 435 \\
\hline 38 & 233 & 67.78 & 309 & 1.18 & 473 \\
\hline 37 & 196 & 70.73 & 312 & 1.23 & 510 \\
\hline 31 & 165 & 75.64 & 317 & 1.32 & 541 \\
\hline 35 & 130 & 79.57 & 321 & 1.39 & 576 \\
\hline 38 & 92 & 86.44 & 328 & 1.51 & 614 \\
\hline 17 & 75 & 93.32 & 335 & 1.63 & 631 \\
\hline
\end{tabular}


3.2.3 One-Day Water Drinking Angle Test

Table 3. One-Day Water Drinking Angle

\begin{tabular}{|c|c|c|c|c|c|c|c|c|}
\hline $\begin{array}{c}\text { Value of } \\
\text { Starting } \\
\text { Point }\end{array}$ & $\begin{array}{l}\text { Value of } \\
\text { Highest } \\
\text { Point }\end{array}$ & $\begin{array}{l}\text { Angle } \\
\text { of } \\
\text { Starting } \\
\text { Point } \\
\quad\left({ }^{\circ}\right)\end{array}$ & $\begin{array}{l}\text { Angle } \\
\text { of } \\
\text { Highest } \\
\text { Point } \\
\left({ }^{\circ}\right)\end{array}$ & $\begin{array}{l}\text { Tangent } \\
\text { of } \\
\text { Starting } \\
\text { Point }\end{array}$ & $\begin{array}{l}\text { Tangent } \\
\text { of } \\
\text { Highest } \\
\text { Point }\end{array}$ & $\begin{array}{l}\text { Water } \\
\text { Volume } \\
\text { of } \\
\text { Starting } \\
\text { Point } \\
\quad \text { (ml) }\end{array}$ & $\begin{array}{l}\text { Water } \\
\text { Volume of } \\
\text { Highest } \\
\text { Point } \\
\text { Starting } \\
\text { Point } \\
(\mathrm{ml})\end{array}$ & $\begin{array}{l}\text { Water } \\
\text { Drinking } \\
\text { amount } \\
\quad(\mathrm{ml})\end{array}$ \\
\hline 270 & 279 & 14.00 & 38.32 & 0.25 & 0.79 & 86.81 & 274.33 & 187.52 \\
\hline 279 & 285 & 38.32 & 44.21 & 0.79 & 0.97 & 274.33 & 336.84 & 62.51 \\
\hline 285 & 299 & 44.21 & 57.96 & 0.97 & 1.6 & 336.84 & 760.57 & 423.73 \\
\hline 300 & 309 & 58.94 & 67.78 & 1.66 & 2.45 & 762.17 & 775.71 & 13.54 \\
\hline 309 & 316 & 67.78 & 74.66 & 2.45 & 3.64 & 775.71 & 784.21 & 8.50 \\
\hline 301 & 314 & 59.93 & 72.69 & 1.73 & 3.21 & 763.90 & 781.98 & 18.08 \\
\hline 296 & 315 & 55.01 & 73.68 & 1.43 & 3.4 & 496.58 & 795.80 & 299.22 \\
\hline 309 & 331 & 67.78 & 89.39 & 2.45 & 93.92 & 775.71 & 793.60 & 17.89 \\
\hline 298 & 316 & 56.98 & 74.66 & 1.54 & 3.65 & 758.86 & 784.26 & 25.40 \\
\hline 310 & 331 & 68.76 & 89.39 & 2.57 & 93.92 & 776.98 & 793.60 & 16.62 \\
\hline 281 & 292 & 40.28 & 51.09 & 0.85 & 1.23 & 295.17 & 427.13 & 131.96 \\
\hline 292 & 303 & 51.09 & 61.89 & 1.23 & 1.84 & 427.13 & 766.34 & 339.21 \\
\hline 299 & 309 & 57.96 & 67.78 & 1.6 & 2.45 & 760.57 & 775.71 & 15.14 \\
\hline
\end{tabular}

\subsection{Data Analysis}

\subsubsection{Experiment of Function Relationship between Angle and Voltage Value}

From the experimental data and the scatter plot, the relationship between the tilt angle and the voltage value can be derived. Through the observation of the scatter plot, it can be divided into two parts. Taking the angle of $35^{\circ}$ as the critical value, the two-part function relation was obtained separately. Through analysis, it can be concluded: 


$$
V(x)=\left\{\begin{array}{c}
\frac{2}{7} \theta+266(0 \leq \theta \leq 35) \\
\frac{56}{55} \theta+240.4(35<\theta \leq 90)
\end{array}\right.
$$

3.3.2 Experiment of Function Relationship between Angle and Water Drinking Amount

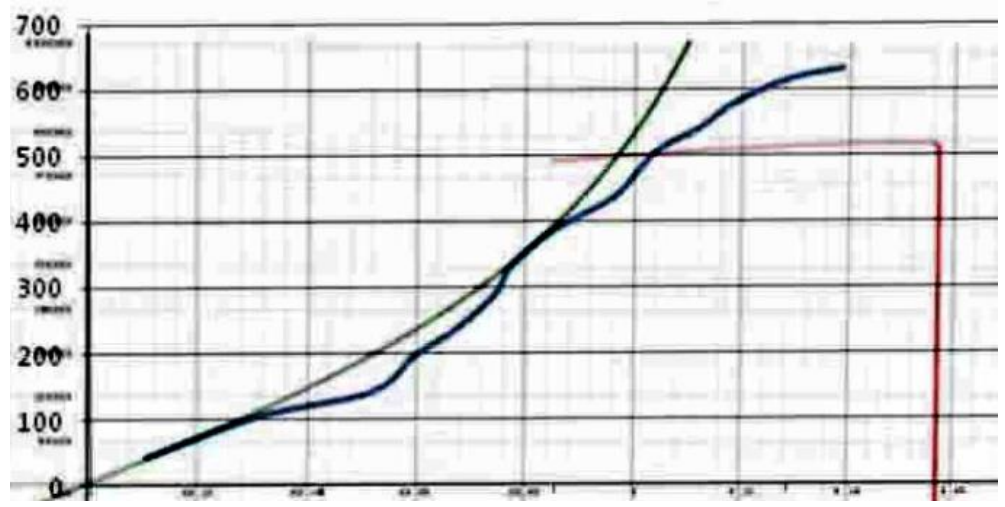

Figure 1. Comparison between the actual and modeled relationships between angles and amount of drinking water

The actual relationship between the angle and amount of drinking water is compared with the modeled on, as is shown in Figure 1. It can be seen that they both have the same trend. The slope of the actual function graph was generally lower than the model.

To verify whether the function graph parsed by modeling is available for real life, after the second experiment and the function graph were obtained, the comparison was carried out again. It was found that the actually obtained function relationship graph fluctuated around the function graph parsed by modeling.

Through actual measurement, it was found that the total volume of the cup was $706 \mathrm{~mL}$. However, based on the model, the total volume of the cup was approximately $796 \mathrm{~mL}$. This means that there was a difference of $90 \mathrm{~mL}$ between the actual amount of drinking water and the modeled value. After plotting the two on a scatter plot, a linear function was used to find the variance, which is higher than 0.9, as is shown in Figure 2. Therefore, it can be concluded that the angle and the amount of water drinking function obtained through the modeling analysis is in a good agreement with the experiment, and can be used in real life. 


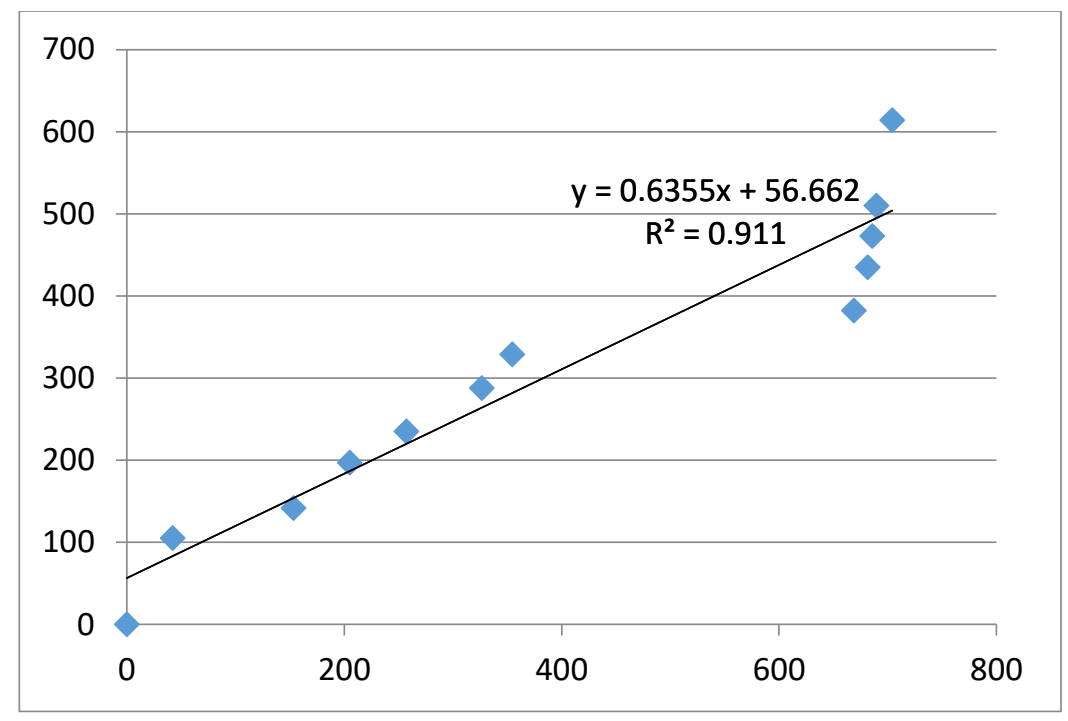

Figure 2. Correlation Analysis of the Relationship between Angle and Water Drinking Amount of the test and model.

3.3.3 Analysis of one-day simulation curve

Table 4. Analysis of One Day Simulation Subsections

\begin{tabular}{|c|c|c|c|c|c|}
\hline No. & $\begin{array}{c}\text { Voltage } \\
\text { Value }\end{array}$ & $\begin{array}{l}\text { Duration } \\
\text { (s) }\end{array}$ & $\begin{array}{l}\text { Speed } \\
(\mathrm{ml} / \mathrm{s})\end{array}$ & $\begin{array}{c}\text { Amount } \\
(\mathrm{ml})\end{array}$ & Analysis \\
\hline 1 & $196-256$ & 1.5 & 125 & 187.52 & $\begin{array}{l}\text { It was the first snip of water after } \\
\text { getting up, the elderly was relatively } \\
\text { thirsty }\end{array}$ \\
\hline 2 & $229-288$ & 1.48 & 42.38 & 62.51 & Small amount, slow speed \\
\hline 3 & $229-382$ & 3.83 & 110.63 & 423.73 & $\begin{array}{l}\text { The elderly drank water at breakfast } \\
\text { with a large amount. The elderly } \\
\text { drank fast for a long time. The } \\
\text { elderly was relatively thirsty. After } \\
\text { the analysis of this special situation, } \\
\text { it can be found that the salt content } \\
\text { of breakfast was too high, resulting } \\
\text { in the large amount of drinking } \\
\text { water }\end{array}$ \\
\hline 4 & $200-263$ & 1.58 & 8.60 & 13.54 & Small amount, slow speed \\
\hline 5 & $187-241$ & 1.35 & 6.30 & 8.5 & Moring diet helped digestion \\
\hline 6 & $220-305$ & 2.13 & 8.49 & 18.08 & Long time, small amount, slow speed \\
\hline 7 & 301-345 & 1.10 & 272.02 & 299.22 & The elderly drank water after lunch \\
\hline 8 & $157-325$ & 2.07 & 8.64 & 17.89 & Long time, small amount, fast speed \\
\hline 9 & $156-245$ & 3.18 & 7.98 & 25.40 & Long time, small amount, fast speed \\
\hline 10 & 183-315 & 3.3 & 5.04 & 16.62 & Long time, small amount \\
\hline 11 & $152-257$ & 2.63 & 13.66 & 131.96 & Long time, large amount, fast speed \\
\hline
\end{tabular}




\begin{tabular}{cccccl}
\hline 12 & $170-297$ & 3.18 & 8.64 & 339.21 & $\begin{array}{l}\text { Long time, large amount, fast speed, } \\
\text { which was caused by snacks after } \\
\text { dinner }\end{array}$ \\
\hline 13 & $160-205$ & 1.3 & 13.4 & 15.14 & Long time, small amount, slow speed \\
\hline
\end{tabular}

3.3.4 Analysis of water drinking for the elderly

Table 5. Basic Information of the Older Adults

\begin{tabular}{cccc}
\hline No. & Gender & Age & Chronic Diseases \\
\hline A & Male & 81 & Hypertension, Kidney Disease \\
\hline B & Female & 78 & Heart Disease, Parkinson's Disease \\
\hline C & Female & 83 & Cerebral Infarction, Diabetes \\
\hline D & Male & 76 & Arthritis, Malignant Tumor \\
\hline E & Female & 84 & Alzheimer, Hypertension \\
\hline
\end{tabular}

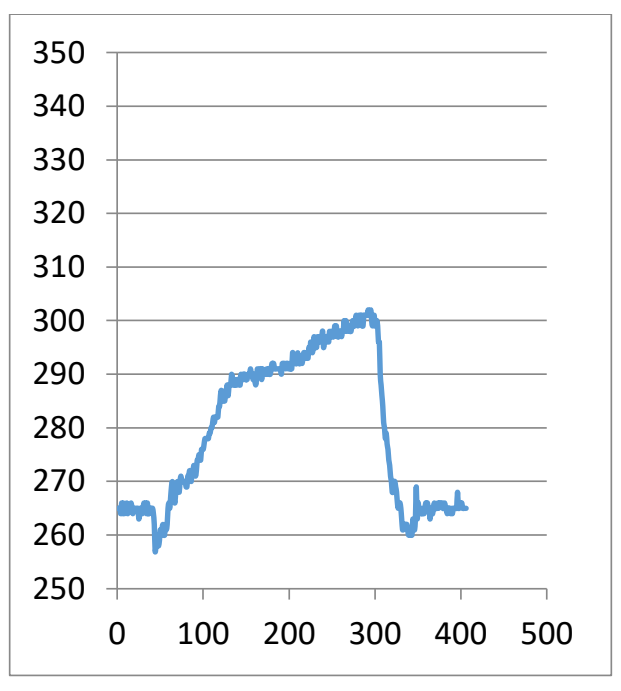

Figure 3. Water Drinking Situation for the Elderly A 


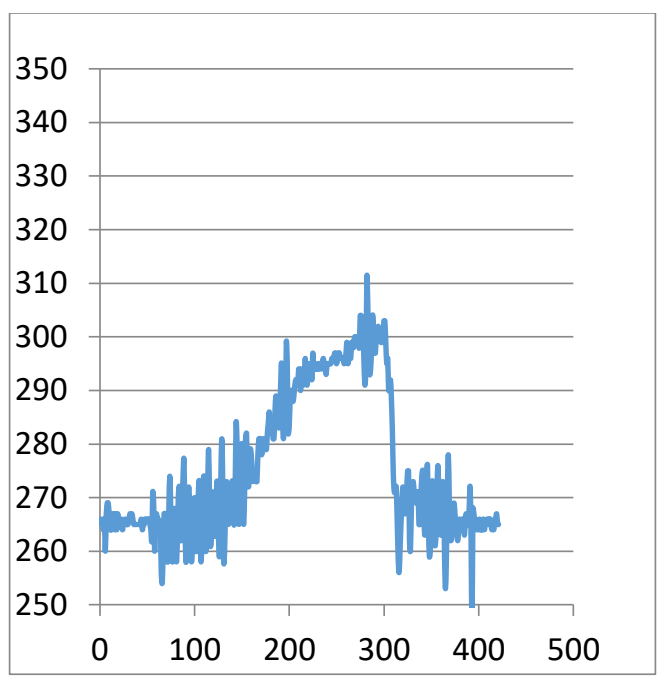

Figure 4. Water Drinking Situation for the Elderly B

Comparing the two older adults A and B with the normal water drinking situation in Figure 3 and 4, it can be seen that there was tremor and unstable posture when the adult $B$ held the cup. After investigating the adult B, it can be known that she was suffering from Parkinson. By observing the change of the angle sensor voltage value, it can be judged that the old adult's hand was shaking. He may have Parkinson's symptoms. The data changes can help medical staffs diagnose the physical condition of the elderly and perform the early treatment.

\section{Conclusion}

After testing water intake sensor in a nursing care center, we could say that the device we designed will provide daily water intake tracking to family doctors for the elderly to review their drinking habit regularly. Those data could help doctors make better decisions to care for the elderly on a daily basis. However, there are some limitations of the monitor. More effects related to water intake should are considered and added in such as material of sensor, cup size, how to service nursing care centers. This is only our first step on how to improve the elderly's hydration wellness. We will continue to improve the design and get more feedback from the users.

\section{References:}

Batmanghelidj, F. (1997). Your Body's Many Cries for Water. Falls Church: Global Health Solutions, Inc. Chinese Nutrition Society. (2017). The Chinese Dietary Guidelines. Beijing: People's Medical Publishing House.

Popkin, B. M., D'Anci, K. E., \& Rosenberg, I. H. (2010). Water, hydration, adn health. Nutrition Reviews, 68(8), 439-458. 